\title{
Discussion on the Planning and Designing of Electric Power System
}

\author{
Xize $\mathrm{Li}^{1,}$, Jiange $\mathrm{Li}^{2}$, b \\ ${ }^{1}$ Postdoctoral Research Center, CCISR, Beijing Jiaotong University, Beijing, 100044,China \\ ${ }^{2}$ Postdoctoral Research Center, CCISR, Beijing Jiaotong University, Beijing, 100044,China

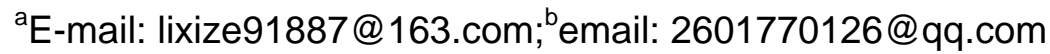

Keywords: Electric Power System; Planning and Designing; Principles; Methods

\begin{abstract}
This paper gives an introduction to the main content of the planning and designing of electric power system in electric power engineering as well as discussion on the principles and methods for the planning and designing of electric power system in electric power engineering. It aims to improve the reasonability and the designing of electric power project in the electric power system and ensure the security and effectiveness of the electric power engineering system.
\end{abstract}

\section{Introduction}

The planning and designing of electric power system serves as a key part in the designing of power electric engineering, and its quality has a direct influence on the normal operation of the electric engineering system. The planning of electric power system provides an important guarantee for a rapid, stable and sustainable development of the electric power industry. An overall and long-term electric power development plan as well as the planning and designing of electric power system is closely related to the rational utility of the investment in electric power industry and the economic efficiency of the resources and energy utilization, serves as an important guarantee for the security of power grid and economic operation, and is a requisite for sustainable development of the electric power industry. For the planning and designing of electric power system to better play its fundamental role in the development of electric power, we have done a primary research and summarized some reviews and opinions on the application of the planning and designing of electric power system in the designing of electric power project.

\section{Major Contents of Planning and Designing the Electric Power System}

The planning of electric power system is a complicated project that runs through the whole electric power engineering system and involves a broad scope and many influence factors. In terms of time, there are short-term, medium term and long term planning and designing of electric power engineering system. The major contents of planning and designing the electric power system are : generation expansion planning and output, the balance of power energy volume, system access plan and electric-related calculation.

\subsection{Planning of Power Sources}

The planning of power sources is a critical part in the planning and designing of electric power system. The planning of power sources means to understand the specific situation and environment around the project and carry out the planning work before the implementation of the power electric project. The planning of power sources mainly include larger electricity power enterprises and smaller electricity power enterprises, which requires planning according to the specific scales of electricity power enterprises and carry out research and planning of the output of power according to different hydrological periods so as to optimize the allocation of resources.

\subsection{Analysis of the Output}

At the preliminary stage of the project construction, designers need to study the distribution of power grids around the project, study the power output in order to carry out an overall analysis of the electric power project and provide scientific basis for electric power system construction. The power suppliers for the electric power system mainly include local power suppliers and unified 
power suppliers. The power electric system of the local power supplier is relatively small while that of the unified power supplier is relatively large. The application of power source is different according to different hydrological periods. Therefore, while analyzing the power output, it is necessary to consider the specific situation of application, as well as analyze and discuss the output of power source according to the actual situation of the electric power system to ensure that the design is scientific and feasible.

1.3 Balance of Electric Power and Energy

Usually the balance of electric power and energy has certain restriction on the planning and designing of the electric power system. First of all, after a prediction about the power load and getting an overall understanding of the output data, designers can have an equilibrium calculation about the electric power and energy of the power source and carry out detailed analysis and statistics of the results to facilitate the layout of the electric power project and design of its scale. Second, when the load prediction has determined the maximum load, we can calculate the surplus and deficit of electric power and energy according to different cases of the power source to get the generated energy needed in the electric power engineering system and choose the appropriate transformer according to actual situations. Meanwhile, we need to consider the exchanges between the electric power and energy and adjust the capacity of transformers according to actual changes.

1.4 System Access Plan

In accordance with features of the original network in which the project is located, load distribution and the development planning of the power grid, designers of the power system should illustrate the position and role of project engineering in electric power system. Then they should propose the alternative scheme for the project access to the power system guided by the power system planning and the approval comments from the government departments. While discussing the system access plan, designers should consider the principles of integrating the remote areas with the nearer ones, taking a comprehensive view and save the land, energy saving and consumption reducing, and the application of new technologies on power grids. At the same time, designers should specify the layout and scale of all schemes of the project engineering, the year of putting into operation, the power grids in the near-region, the operation mode and supply voltage, etc.

1.5 Electrical Calculation

Electrical calculation is an important application of the electric power system planning and designing in the design of electric power engineering. Electrical calculation generally includes load flow calculation, stability calculation, and reactive compensation calculation. Load flow calculation refers to the calculation based on the power and voltage in the power network. By load flow calculation, designers can specify the operating mode of the power system and have an overall control of all components in the system, which will be greatly beneficial to the following relay protection and stability calculation. Guided by the requirements for the electric power engineering, stability calculation makes simulation analysis of various failure conditions in the power system so as to ensure the stability of the power system. Short-circuit current calculation refers to the checking calculation on given grid structures, which provides an overall verification for the abnormal current values generated by the electronic components arising with possible short circuits. Short-circuit current calculation provides some help for the model selection of electrical equipments in the later stage. Reactive compensation can provide corresponding reactive power for the inductive load in the power grid, so as to reduce the energy consumption during the transmission of reactive power. In specific electric power projects, it is necessary to, based on the reactive balance, provide corresponding reactive compensation installation overall capacity and grouping capacities, then analyze the near-region reactive balance in the efforts of planning and designing electric power system.

\section{Basic Principles for Planning and Designing the Electric Power System}

The electric power system should supply adequate, reliable and premium-quality electric energy and the economic efficiency, reliability and flexibility are the necessary qualities of the electric 
power system. Therefore, it is the basic requirement for the planning and designing of electric power system to have these qualities.

\subsection{Economic efficiency of the Electric Power System}

One of the major tasks in the work of planning and designing the electric power system is to ensure the economic efficiency of power grid construction, which includes the transportation and supply of fuels; generation and transmission of electrical energy; the one-time investment and depreciation of equipments for power generation, transmission and transformation; the loss of energy in the transportation process; and other operating costs, etc. In planning and designing the power system, the operating cost is calculated in the way of production simulation and the general requirement is to keep the annual cost as low as possible. As for large-scale planning and designing projects of the power system such as the cross-region power transmission project, long-distance power transmission and plant construction, the financial analysis should be made for the projects in order to ensure their loan repay ability and economic efficiency.

\subsection{Reliability of Electric Power System}

The major points of the reliability of electric power system are as follows: (1) Adequacy in power supply to users. Adequacy in power supply means the continuity of power supply in meeting with electricity consumption load of a certain quantity. While the loss of load probility (LOLP) has been generally adopted as an evaluation criterion for the adequacy of electric power supply in the international community, China has been using the concept of "installed capacity percentage reserve" to represent the adequacy condition of power supply. (2) Safety in power supply to users. Safety in power supply means the severity of malfunction and disturbance that the system can sustain while keeping power supply in a safe and stable way, which generally refers to the fault conditions stipulated in related regulations. One of the major tasks in the development and planning electric power system is to ensure that the system should meet certain safety standards through the safety check in electric power system, including the steady N-1 safety check and transient stability calculation.

\subsection{Flexibility of Electric Power System}

Many uncertain factors will occur in developing and planning electric power system. And after the planning and designing, some changes may occur in the operation of infrastructure construction project as well as the power supply, load and network condition in the system. In this case, the design of electric power system should still be able to meet the required technological and economic norms without big modifications. This is the flexibility of electric power system in adapting to the changes in infrastructure construction conditions.

\section{Methods of Electric Power System Planning}

\subsection{Analysis of Basic Conditions}

Analysis into the basic conditions of electric power industry is primarily conducted in the perspectives of power load demand, resource development and facility manufacturing, so as to effectively estimate the costs and other issues in the electric power system. The three basic conditions in the development of electric power industry are power load demand, license of development and transportation conditions for power resources, as well as the manufacturing and timely supply of facilities for power generation and transformation.

The increase in power load represents a direct reflection of the power demand in national economic development and social activities, thus predicting and planning the annual power demand in different sectors also serves as a prediction of the prospective development in national economy and social activities. In this sense, the accuracy in predicting the development of power load depends on the accuracy in predicting the development of all national economic sectors and social activities. When the load quantity demand within the planning period is determined, the development speed in electric power industry is also determined. Therefore, the development status of power load is the most critical basic condition in making the plan and design of electric power system. Except for the prediction and analysis in quantitive terms, the load characteristics, determined by its structure, and the analysis of it can be of important significance in determining 
the operation mode of electric power system, the power grid structure, peak-load regulation and voltage regulation characteristics.

Power resources refer to energy resources that can be used to generate power such as coal, hydraulic power, nuclear energy, wind power and petroleum. In fact, the structure, reserves as well as the development and transportation conditions of power resources determine the national policies for energy and power development, and at a macro level further determine the development direction of the electric power industry for a nation. The conditions of facility supply include the national level and capability of manufacturing the complete equipments for power transmission and transformation as well as the possibility of introducing such equipments from abroad. The development speed and scale of electric power industry is partly subject to the conditions of facility supply.

\subsection{Analysis of Basic Functions}

The analysis into basic functions of power grid refers to the analysis into all parts of the power network and the features and functions of major grid structures, and timely analysis into functions of the grid structures as well as other facilities according to the update status of the power system. Analysis into the basic functions should be conducted at different levels. The primary level is to analyze the supply area of the whole network, the construction site and functions of the power sources, as well as the relationship of power transmission or reception between sub-regional power grids. The second level is to analyze the reasonable transmission range of major power sources, the flowing direction of power and its corresponding grid structures. And the last level is to analyze the situation of regional power grids. In the process of analysis, it should be noted that with the development of the electric power system, the functions of different parts of the power grid including whether the power sources, grid structures or power transmission lines are all subject to changes. For instance, with the development of load in the region, a district major power station can grow to be a regional one. For another instance, with the increase in loop numbers, the continual access of power substations in between, and the occurrence of higher-level voltage, a major grid structure can also grow to be a regional network.

\subsection{Analysis of Basic Patterns}

The analysis into basic patterns of the electric power system refers to analyzing the structures of power grid and make relevant designing of the structures in accordance with the specific practical situations. The structure of power grid means the mode of connection between power stations and substations, of which the three fundamental patterns are radiative, chain form and ring-type. The structure of power grid is primarily determined by the distribution of power stations and their loads, and the geographical coverage of power grid. The fundamental principle in designing the structures of power grid is different design for different levels and districts, i.e. power grids in different voltage classes constitute different levels, the sub-level power grids in different regions split into different district power grids, and the district power grids are equipped with adequate voltage support and reactive power reserves by themselves.

\subsection{Dynamic Analysis, i.e. Elastic Analysis or Analysis of Variable Factors}

Dynamic analysis, i.e. elastic analysis or analysis of variable factors, mainly refers to planning the adaptability of power grids when there are gaps between the actual development process and designing expectations of power grids. The variable factors include occasions where the actual load growth exceeds or lower than expected, the process or order of power source construction changes, the operation time of main power transmission lines is earlier or later than expected. In this case, a rolling approach should be taken for corrections in planning the electric power system.

\subsection{Analysis of Restrictive Conditions}

During the process of making planning programs for the electric power system, restrictive conditions that will affect the success of planning programs should be paid with particular attention. Major restrictive conditions are restrictive factors in physiographic conditions, water-supply source conditions, occasions where the construction process of coal mines fail to meet the energy demand of power stations and where the construction process of highways, railways or wharfs in the region where the power stations or substation are located. In addition, if main power transmission lines run 
across the river, or difficulties occur in manufacturing electrical equipment, these cases can also form restrictive factors in planning programs for the electric power system.

3.6 Analysis of Reliability and Economical Efficiency

At this moment in China, no reliability standard in the phases of power generation expansion planning and power grid planning has been formulated. There is "Principles in Making Power Development Planning" in the phase of power system planning, and "Technical Guide for Electric Power System", "Safety and Stability Guide for Electric Power Systems" as well as "Technical Code for the Design of Electric Power Systems" in the phase of power system designing, which have set standards for the safe and steady operation of electric power systems. As required in the standards, the technical and economic characteristics of the designed system should be evaluated in a comprehensive way through the methods of load flow calculation, reactive compensation and voltage adjustment calculation, system stability analysis, N-1 network safety check, power frequency overvoltage and secondary arc current calculation, short circuit current calculation and project economic evaluation calculation, and then a best program should be proposed correspondingly. The planned and designed electric power systems should meet the basic requirements for economical efficiency, reliability, and flexibility.

\section{Conclusion}

In conclusion, the planning and designing of electric power system is of significant importance to the design of electric power engineering and serves as a strong guarantee for the normal operation of overall electric power system. Therefore, power enterprises must give high priority to the planning and designing of electric power system, do a good job in the earlier stage planning of electric engineering and make scientific and reasonable planning and designing programs for the electric power system. In addition, they must make a point of collecting experiences and lessons in practical work, so as to steadily improve the quality and level of electric power system planning and designing and promote the sustainable development of electric power system planning and designing in the design of electric power engineering. As the times advances and society progresses, we should keep making innovations in the planning and designing of electric power system. Only in this way can we adapt the power system to the updating demand of national economy and social development in our efforts to promote the sound, strong and sustainable development of the electric power industry.

\section{References}

[1] Xifan Wang. Optimal Planning of Power System [M]. Beijing: China Water \& Power Press, 1990.

[2] Hongbo Sun. Power Grid Planning [M]. Chongqing: Chongqing University Press, 1996.

[3] Gang Liu, Xueshen Wang. Research on Electric Power Technology and Electric Power System Planning —With the Example of Smart Grid [J]. China Technology. 2011(09):24-26.

[4] Junqiang Zhong. Analysis into the Application of Electric Power System Planning and Designing in Electric Power Engineering Design [J]. GD Science \& Technology. 2012(3):66-67.

[5]Chongqing Kang, Qing Xia, Boming Zhang.Research Overview of Load Forecasting in Electric Power System and Discussion on the Developing Direction. [J]. Automation of Electric Power Systems,2004,28(17):13-15. 